\title{
Efficacy of aqueous leaf extracts and synthetic insecticide on pod-sucking bugs infestation of cowpea (Vigna unguiculata (L.) Walp) in the Guinea Savanna Region of Nigeria
}

\author{
Michael M. Degri, Duna M. Mailafiya*, Joshua W. Wabekwa
}

Department of Crop Protection, University of Maiduguri, Maiduguri, Nigeria; *Corresponding Author: dmailafiya@gmail.com

Received 12 May 2013; revised 25 June 2013; accepted 17 July 2013

Copyright (c) 2013 Michael M. Degri et al. This is an open access article distributed under the Creative Commons Attribution License, which permits unrestricted use, distribution, and reproduction in any medium, provided the original work is properly cited.

\section{ABSTRACT}

Pod-sucking bugs (PSBs) infestation by Anoplocnemis sp./Riptortus sp./Clavigralla sp./Nezara viridula (Linnaeus) greatly limits cowpea (Vigna unguiculata (L.) Walp) production throughout sub-Saharan Africa. The efficacy of aqueous leaf extracts (ALEs) (5 percent weight/volume concentration) of three botanicals and one synthetic insecticide against PSBs infestation was thus evaluated. The botanicals tested include Azadirachta indica A. Juss, Chromolaena odorata (L.) and Ricinus communis (L.), whilst the synthetic insecticide was Uppercot 500 EC (Lambda cyhalothrin $30 \mathrm{~g}$ + Dimethoate $250 \mathrm{~g}$ ). The effects of these treatments on the number of PSBs/ pods/seeds, pod/seed weight and grain yield were assessed during 2008 and 2009 rainy seasons in Bayo, Borno State, Guinea Savanna region, Nigeria. The number of PSBs was lower on crops treated with Uppercot 500 EC (0.00 - 0.31). This was followed by crops treated with the ALEs of $A$. indica/C. odorata $(0.31-1.33)$ and $R$. communis $(0.72$ - 3.72) than the untreated (3.06 5.64) ones. The number of pods/pod weight per plant, seeds/seed weight per pod and total grain yield were generally higher on cowpea crops treated with Uppercot $500 \mathrm{EC}(26 / 17 \mathrm{~g}, 14 / 19 \mathrm{~g}$ and $1618 \mathrm{~kg}$ ). This was followed by crops treated with the ALEs of $A$. indica/C. odorata (23 - 25/14 $15 \mathrm{~g}, 12-13 / 15 \mathrm{~g}$ and $1268-1310 \mathrm{~kg})$ and $R$. communis $(21 / 13 \mathrm{~g}, 11 / 14 \mathrm{~g}$ and $972 \mathrm{~kg})$ than the untreated $(16 / 9 \mathrm{~g}, 7 / 10 \mathrm{~g}$ and $312 \mathrm{~kg})$ ones. Although Uppercot 500 EC was most effective in protecting cowpea against PSBs attack, the ALEs of $A$. indica and $C$. odorata appreciably protected treated crops against infestation, giving relatively high total grain yield. Both botanicals can thus serve as alternatives to synthetic insecticides for managing PSBs attack on cowpea.

Keywords: Cowpea; Pod-Sucking Bugs; Infestation; Aqueous Leaf Extract; Synthetic Insecticide; Grain Yield

\section{INTRODUCTION}

Cowpea (Vigna unguiculata (L.) Walp) is one of the most important leguminous crops widely grown in the tropics, especially in the savanna zones of West Africa and other drier regions of the world [1,2]. Cowpea is a primary source of plant protein for humans, as well as fodder for livestock. It also serves as a cover crop, important for nitrogen fixation [3].

Majority of people in the developing countries including Nigeria are engaged in cowpea production, but with low productivity mainly due to insect pest attack at flowering and post-flowering (podding) stages [4-6]. Attacks by post-flowering insect pests contribute greatly to low cowpea production in the savanna region of northern Nigeria [5-9]. Damage arising from flowering and podding insect pests such as the pod borers and pod-sucking bugs (PSBs) often leads to severe losses of cowpea grains in the field $[10,11]$. The control of infestation by these pests should therefore improve or raise cowpea production by several folds in the northern savanna regions of Nigeria.

Due to the generally high cost of synthetic insecticides and their hazardous impact on the environment and human applicators, biopesticides are much more preferred 
for insect pest control [12,13]. Plant extracts effective in managing insect pest attacks can therefore serve as alternatives to synthetic insecticides application [5,6]. This study therefore evaluated the efficacy of aqueous leaf extracts (ALEs) of three plant species including neem (Azadirachta indica A. Juss), Siam weed (Chromolaena odorata (L.)) and castor bean (Ricinus communis (L.)) in controlling PSBs infestation of cowpea in Bayo, Borno State, Guinea Savanna Region, Nigeria.

\section{MATERIALS AND METHODS}

\subsection{Location}

Field studies were carried out during 2008 and 2009 rainy seasons at the Borno State Agricultural Development Programme (BOSADP) research sub-station in Briyel, Bayo Local Government Area $\left(11^{\circ} 51^{\prime} \mathrm{N}\right.$ and $\left.13^{\circ} 15^{\prime} \mathrm{E}\right)$, Borno State, situated in the Guinea Savanna region of Nigeria.

\subsection{Collection of Materials and Preparation of Extracts}

Seeds of the early maturing cowpea variety, Banjiram, with red seed coat colour were purchased from BOSADP. Fresh and clean leaves of the botanicals neem, Siam weed and castor bean were obtained from different farms in Briyel, Bayo Local Government Area. The synthetic insecticide, Uppercot 500 Emulsifiable Concentrate (EC) (Lambda cyhalothrin $30 \mathrm{~g}+$ Dimethoate $250 \mathrm{~g}$ ), used in this study was obtained from the agro-chemical distributor, African Cotton Company Limited (AFCOTT), in Maiduguri, Borno State.

The fresh and clean plant leaves obtained were pounded into a paste using pestle and mortar. Five gram (g) paste of each plant material (neem, Siam weed and castor bean) was weighed and poured into a 5000 milliliters (ml) conical flask containing one liter of distilled water. The mixture (paste and water) was manually stirred vigorously for ten minutes and then sieved after two hours using a Muslin cloth to get the 5 per cent (\%) weight (w) of paste per volume (v) of water concentration (w/v) extract $[14,15]$.

\subsection{Experimentation}

The field was cleared, ploughed, harrowed and ridged at 0.75 meters (m) apart, and afterwards divided into plots separated by an alley of $2.0 \mathrm{~m}$ apart. Each plot was $4.0 \mathrm{~m} \times 3.0 \mathrm{~m}\left(12.0 \mathrm{~m}^{2}\right)$. Cowpea seeds were sown at 2 3 centimeters $(\mathrm{cm})$ depth, and also at $30 \mathrm{~cm}$ intra row and $75 \mathrm{~cm}$ inter row spacing. Each treatment was replicated four times and the entire field laid out in a randomized complete block design. Weeding was done using hand hoe, and carried out at three weeks interval.
Uppercot 500 EC (1.5 g active ingredient/hectare) and the ALEs (5\% w/v concentration) of A. indica, C. odorata and $R$. communis were applied fortnightly using the Knapsack sprayer, CP 15. Application of the above test materials commenced with the onset of podding, and was maintained fortnightly when the previous application(s) must have waned off. Each plot was sprayed with a single designated test material. The number of PSBs found on ten randomly selected plants per plot was counted at two, four, six and eight days after application (DAA). The number of pods harvested per plant were counted, and then weighed (g) with a Mettler balance. Following the shelling and winnowing of harvested pods, the number of seeds per pod were also counted and weighed as described above.

\subsection{Data Analysis}

Data collected on the number of PSBs, pods and seeds, as well as the weight of pods, seeds and total grain yield were subjected to the analysis of variance (ANOVA). The means of the treatments were separated using the least significant difference (LSD) at 5\% level of probability as described by Gomez and Gomez [16].

\section{RESULTS AND DISCUSSION}

The number of PSBs found attacking cowpea crops per plot during the podding stage are presented in Table 1. The results showed that at two, four, six and eight DAA, the mean numbers of PSBs per plot was higher on untreated (3 - 6) cowpea crops. This was followed by those treated with the ALEs of $R$. communis ( 1 - 4), A. indica or $C$. odorata $(0-1)$ and lower on those treated with Uppercot 500 EC (0). Also, the mean number of PSBs at two to eight DAA was 1 - 6/2 - 4/4 - 5/4 - 10 times higher on cowpea treated with the ALEs of $A$. indica, $C$. odorata and $R$. communis than the untreated crops. Furthermore, the mean number of PSBs was 4 - 10

Table 1. Effect of three aqueous leaf extracts and Uppercot 500 EC on the mean number of pod-sucking bugs per plot at different days after application.

\begin{tabular}{ccccc}
\hline \multirow{2}{*}{ Treatment } & \multicolumn{4}{c}{ Number of pod-sucking bugs/plot } \\
\cline { 2 - 5 } & 2 DAA & 4 DAA & 6 DAA & 8 DAA \\
\hline Chromolaena odorata & 0.36 & 0.67 & 0.67 & 1.32 \\
Azadirachta indica & 0.31 & 0.67 & 0.88 & 1.33 \\
Ricinus communis & 0.72 & 0.78 & 2.67 & 3.72 \\
Uppercut 500 EC & 0.01 & 0.00 & 0.00 & 0.31 \\
Control & 3.06 & 3.09 & 3.82 & 5.64 \\
Standard Error $( \pm)$ & 0.03 & 0.02 & 0.03 & 0.04 \\
Least Significant & 0.05 & 0.04 & 0.06 & 0.08 \\
Difference $(0.05)$ & & & & \\
\hline
\end{tabular}

${ }^{1}$ Days after application; ${ }^{2}$ Emulsifiable Concentrate. 
and 2 - 3 times less at different DAA on cowpea crops treated with $A$. indica and $C$. odorata than with $R$. communis and also untreated crops. Though, the ALEs of all three botanicals contributed in reducing the number of PSBs on treated cowpea, the extracts of $A$. indica and $C$. odorata were relatively more effective against crops infestation. The ALEs of the two botanicals, therefore, seem to have potent insecticidal properties for checking PSBs infestation and population increase. Botanical insecticides contain compounds with properties that repel, deter or disrupt the growth, feeding or reproductive activities of insect pest on crops $[5,6,10]$. Azadirachtin, a triterpenoid substance from the $A$. indica plant has been generally reported to have repellent, antifeedant, growth inhibitory and toxic or insecticidal activities against a number of insect pests [17]. [18], for instance, found that $1 \%$ and $3 \%$ oil emulsion spray of $A$. indica on rice respectively reduced the incidence of Cnaphalocrocis medinalis and protected developing grains against Leptocorisa acuta. Oil (5\%) sprays of $A$. indica plus its kernel extracts (39\%) have been reported to effectively reduce the population of Helicoverpa armigera in chickpea [19]. The usage of Nemidin-9, an A. indica (70\%)-based formulation, also inhibited larval development of $H$. armigera in chickpea [20]. Phytochemical studies by Matur and Davou [21] showed that the insecticide, Chlopyrifos, and also ALEs of $C$. odorata $(<1 \mathrm{mg} / \mathrm{mL})$ recorded $100 \%$ larval mortality of Simulium spp. Similarly, the mortality of Sitophilus zeamais Motsch. on maize due to dried and pulverized leaves of $C$. odorata (66\% - 75\%) compared appreciably to that caused by the insecticide, Actellic dust (75\%) [22]. In evaluating the bioactivity of C. odorata, [23] found that its ALEs was very strongly positively correlated with the progeny production of S. zeamais and grain weight loss in maize. Insecticidal or acaricidal and antimicrobial agents including quercetin, gallic acid, flavone or kaempferol responsible for pest repellence, deterrence or toxicity have specifically been isolated from the $R$. communis plant [24,25]. Ingestion and contact of the oil emulsion (10\%) of $R$. communis by $P$. xylostella larvae on cabbage resulted in $100 \%$ mortality, and also strongly deterred oviposition (<20 total eggs) 5 DAA [26]. Sorghum seeds treated with hydraulic and ethanolic seed extracts of $R$. communis $(0.1-0.5 \mathrm{ml} / 5 \mathrm{~g}$ seed) repelled $80 \%$ of Tribolium castaneum Herbst adults and also caused 100\% larval mortality 3 DAA [27]. Also, in killing 48\% - 60\% diazinon, deltamethrin and multi-acaricide resistant cattle ticks, Rhipicephalus microplus, the leaf extract of $R$. communis proved to be considerably effective against organophosphate and pyrethroid resistant ticks [25]. Similar to our results, however, other studies have also found the extracts of $R$. communis to be slightly efficacious against certain insect pests. Egg hatchability of Brontispa longissima Gestro, 7
DAA of $R$. communis extracts was higher (70\%) than when treated with Celosia argenea L. and Mikania micrantha H.B.K. (44\% - 54\%) [28]. The treatment of Agave tequilana Weber with hydroethanoholic extracts $(0.1$ - 100,000 ppm) of the leaves/seeds of $R$. communis against Scyphophorus acupunctatus, likewise showed no significant effects on adult mortality and weight loss changes [29]. Altogether, these suggest that the efficacy of $R$. communis at least varies with insect species or the developmental stage, and also the formulation type or combination and concentration tested.

Results of the number of pods harvested and pod weight per plant are presented in Table 2. The number of pods and pod weight produced were higher from cowpea treated with Uppercot 500 EC (26 and $17 \mathrm{~g}$ ). This was followed by those treated with the ALEs of A. indica or C. odorata (23 - 25 and 14 - $15 \mathrm{~g}$ ), R. communis (21 and $13 \mathrm{~g}$ ), and lower on untreated (16 and $9 \mathrm{~g}$ ) crops. The results of the number of seeds obtained or seed weight per pod and total grain yield are presented in Table 3 . Similar to the above trend, the number of seeds and seed weight per pod was greater from cowpea treated with Uppercot 500 EC (14 and $19 \mathrm{~g})$. This was followed by crops treated with the ALEs of $A$. indica or C. odorata (12 and $15 \mathrm{~g}$ ), $R$. communis (11 and $14 \mathrm{~g}$ ) than those from untreated (4 and $10 \mathrm{~g})$ ones. Total yield obtained was three (R. communis $(972 \mathrm{~kg})$ ), four (C. odorata $(1310 \mathrm{~kg})$ and $A$. indica (1268 kg)) and five (Uppercot 500 EC (1618 kg)) times higher from treated than untreated (312 kg) cowpea crops. The overall, lower number and weight of pods/ seeds and total grain yield obtained from untreated cowpea crops indicate greater damage due to attack by the PSBs. Greater general yield of cowpea pods/seeds/total grains obtained from crops treated with both synthetic and botanical insecticides was attributed to the reduction of PSBs infestation or population and feeding activities on these crops $[11,30]$. PSBs feeding during the early podding stages of cowpea often lead to pod abortion/ shriveling or seed damage [31], that culminates in poorpod or -seed set and decreased crop yield. Taken together, the results show that the PSBs remain very

Table 2. Effect of three aqueous leaf extracts and Uppercot 500 EC on the mean number of pods and pod weight per plant.

\begin{tabular}{ccc}
\hline Treatment & $\begin{array}{c}\text { Number of } \\
\text { pods/plant }\end{array}$ & $\begin{array}{c}\text { Pod weight } \\
\text { (g)/plant }\end{array}$ \\
\hline Chromolaena odorata & 23.33 & 14.30 \\
Azadirachta indica & 25.02 & 15.29 \\
Ricinus communis & 20.88 & 12.52 \\
Uppercot 500EC ${ }^{1}$ & 26.08 & 17.33 \\
Control & 15.67 & 8.85 \\
Standard Error $( \pm)$ & 0.04 & 0.05 \\
Least Significant Difference $(0.05)$ & 0.08 & 0.10
\end{tabular}

${ }^{1}$ Emulsifiable Concentrate. 
Table 3. Effect of three aqueous leaf extracts and Uppercot 500 EC on the mean number of seeds and seed weight per pod, and total grain yield of cowpea.

\begin{tabular}{cccc}
\hline Treatment & $\begin{array}{c}\text { Number } \\
\text { of seeds } \\
\text { /pod }\end{array}$ & $\begin{array}{c}\text { Seed } \\
\text { weight } \\
\text { (g)/pod }\end{array}$ & $\begin{array}{c}\text { Grain } \\
\text { yield } \\
\text { (kg/ha) }\end{array}$ \\
\hline Chromolaena odorata & 12.08 & 14.61 & 1267.96 \\
Azadirachta indica & 12.67 & 15.33 & 1310.41 \\
Ricinus communis & 10.62 & 14.38 & 971.85 \\
Uppercot 500EC & 14.02 & 19.33 & 1617.62 \\
$\quad$ Control & 6.84 & 10.17 & 311.70 \\
Standard Error $( \pm)$ & 0.06 & 0.31 & 16.74 \\
Least Significant & 0.12 & 0.67 & 36.48 \\
Difference $(0.05)$ & & & \\
\hline
\end{tabular}

${ }^{1}$ Emulsifiable Concentrate.

important insect pests of the reproductive structures of cowpea crops in the savanna region of Northern Nigeria $[5,6,8,11,14]$. As such, it is imperative to protect the reproductive structures of cowpea crops with, i.e., insecticides (synthetic or botanical) to aid obtain favorable crop yield. Without which, as in this study, cowpea crops may incur PSBs infestation and destruction severe enough to threaten good crop yield. The impact of insecticide spray regimes on insect abundance in cowpea crops grown in North Eastern Nigeria was for instance assessed by [9]. Findings obtained pointed out that the spraying of insecticides at the onset of the podding stage generally reduced insect pests infestation and pod or seed damage, and ultimately increased grain yield. The number of PSBs recorded was $2-3$ and 4 - 9 times much less on cowpea crops treated with the ALEs of $A$. indica and $C$. odorata than with $R$. communis and untreated crops. The total grain yield of cowpea treated with the ALEs of $A$. indica or C. odorata and Uppercot 500 EC were 4 and 5 times respectively higher than those of untreated crops. Also, the total grain yield of cowpea crops treated with the ALEs of $A$. indica and $C$. odorata was 1.3 times higher than those treated with $R$. communis. Having performed better than $R$. communis, the ALEs of A. indica and $C$. odorata have proven to be appreciably effective against PSBs infestation, and as a result, can sustain greater crop yield. Both botanicals can therefore serve as alternatives to synthetic insecticides usage for managing the populations of PSBs on cowpea. Advantageously, these botanicals are readily available in the savanna region of Northern Nigeria. Also, being bio-degradable the bio-insecticides should be friendly or safe to the applicators, farmers, consumers and environment.

\section{CONCLUSION}

In conclusion, the application of the ALEs of A. indica and $C$. odorata from the onset of podding and at fort- nightly intervals, greatly reduced PSBs infestation of cowpea crops. This, in consequence, supported increased total grain yield, which was appreciably close to that from cowpea crops protected with the synthetic insecticide, Uppercot 500 EC. With better general performance than the ALE of $R$. communis, extracts of the above two botanicals can serve as alternatives to synthetic insecticides in checking PSBs infestation and destruction of cowpea crops.

\section{ACKNOWLEDGEMENTS}

The authors are grateful to Mal. Kassim, A.M. and Mr. James, M.O. for assisting with data collection.

\section{REFERENCES}

[1] Singh, S.R. (1990) Insect pests of tropical food crops. John Willey and Sons, Ibadan.

[2] Jefferson, T. (2005) Cowpea: Aversatile crop for hot dry conditions. Thomas Jefferson Agricultural Institute, West Nifong Soulevard, Columbia.

[3] Asiwe, J.A.N. (2009) Needs assessment of cowpea production practices, constraints and utilization in South Africa. African Journal of Biotechnology, 8, 5383-5388.

[4] Singh, B.B., Asante, K., Ajegbe, H. and Mohammed, S.H. (2000) General guide for cowpea cultivation and seed production. Sasakawa Global 2000, Federal Ministry of Agriculture, Abuja.

[5] Ahmed, B.I., Onu, I. and Mudi, I. (2009) Field bioefficacy of plant extracts for the control of post flowering insect pests of cowpea in Nigeria. Journal of Biopesticides, 2, 37-43.

[6] Degri, M.M., Maina, Y.T. and Richard, B.I. (2012) Effect of plant extracts on post flowering insect pests and grain yield of cowpea (Vigna unguiculata (L.) Walp) in Maiduguri Semi Arid zone of Nigeria. Journal of Biology, Agriculture and Healthcare, 2, 46-51.

[7] Manawadu, D. and Sharah, H.A. (1990) Review of insects associated with cowpea: The case of Maiduguri in the semi-arid zone of Nigeria. Nigerian Journal of Entomology, 11, 100-111.

[8] Amatobi, C.I. (1994) Field evaluation of some insecticides for the control of insect pests of cowpea (Vigna unguiculata (L.) Walp.) in the Sudan Savanna of Nigeria. International Journal of Pest Management, 40, 13-17. http://dx.doi.org/10.1080/09670879409371846

[9] Sharah, H.A. and Ali, E.A. (2008) Impact of insecticide spray regimes on insect abundance in cowpea (Vigna unguiculata (L.) Walp.) in North Eastern Nigeria. International Journal of Agriculture and Biology, 3, 255-260.

[10] Oparaeke, A.M. (2005) Studies on insecticidal potentials of extracts of Gmelina arborea products for the control of field pest of cowpea (Vigna unguiculata (L.) Walp). Journal of Plant Protection Research, 45, 68-73.

[11] Dzemo, W.D., Niba, A.S. and Asiwe, J.A.N. (2010) Effects of insecticide spray application on insect pest infes- 
tation and yield of cowpea (Vigna unguiculata (L.) Walp.) in the Traskei, South Africa. African Journal of Biotechnology, 9, 1673-1679.

[12] Fuglie, L.J. (1998) Producing food without pesticides: Local solutions to crop pest control in West Africa. National Council of the Churches of Christ in the United States of America, Church World Service, Technical Centre for Agricultural and Rural Cooperation, Ede, 158p.

[13] Stoll, G. (2001) National crop protection in the tropics. Letting information come to life. F \& T. Mullerbader Fildstadt Publishers, Germany, 208p.

[14] Jackai, L.E.N., Inang, E.E. and Nwobi, P. (1992) The potential for controlling post flowering pests of cowpea (Vigna unguiculata (L.) Walp.) using neem (Azadirachta indica A. Juss). Tropical Pest Management, 38, 56-60. http://dx.doi.org/10.1080/09670879209371646

[15] Emosairue, S.O. and Ukeh, D.A. (1996) Field trials of neem products for the control of okra flea beetles in south eastern Nigeria. African Journal for Plant Protection, 6, 22-26.

[16] Gomez, A.K. and Gomez, A.A. (1984) Statistical procedures for agricultural research. 2nd Edition, John Wiley and Sons, New York.

[17] Debashri, M. and Tamal, M. (2012) A review on efficacy of Azadirachta indica A. Juss based biopesticides: An Indian perspective. Research Journal of Recent Science, 1, 94-99.

[18] Gupta, S.P., Prakash, A. and Rao, J. (1990) Bio-pesticidal activity of certain plant products against rice earhead bug, Leptocorisa acuta Thunb. Journal of Applied Zoological Research, 1, 55-58.

[19] Siddappaji, C., Kumar, A.R.V. and Gangadhar, R. (1986) Evaluation of different insecticidal sprays against the chickpea borer, Heliothis armigera Hubn. Pesticides, 20, 13-16.

[20] Nelson S.J., Sundarababu, P.C., Rajavel, D.S., Srimmannarayana, G. and Geetanjali, Y. (1993) Antifeedant and growth inhibiting effects of azardirachtin-rich neem fractions on Sogatella furcifera Horvath, Spodoptera litura Fabr. and Helicoverpa armigera Hubn. World Neem Conference, 10, 243-252.

[21] Matur, B.M. and Davou, B.J. (2007) Comparative larvicidal property of leaf extract of Chromolaena odorata L (Composidae) and Chlopyrifos (organophosphorus compound) on Simulium larvae. Biomedical and Environmental Sciences, 20, 313-316.

[22] Mbah, O.I. and Okoronkwo, M.O. (2008) An assessment of two plant product efficacy for the control of the maize weevil (Sitophilus zeamais Motschulsky) in stored maize African. Journal of Agricultural Research, 3, 494-498.

[23] Amenga, D.A. (2011) The efficacy of ethanolic root and leaf extract of Chromolaena odorata (L). in controlling Sitophilus zeamais Motschulsky in stored maize. MSc. Thesis, Kwame Nkrumah University of Science and Technology, Kumasi.

[24] Upasani, S.M., Kotkar, H.M., Mendki, P.S. and Maheshwari, V.L. (2003) Partial characterization and insecticidal properties of Ricinus communis L. foliage flavonoids. Pest Management Science, 59, 1349-1354. http://dx.doi.org/10.1002/ps.767

[25] Ghosh, S., Tiwari, S.S., Srivastava, S., Sharma, A.K., Kumar, S., Ray, D.D. and Rawat, A.K. (2012) Acaricidal properties of Ricinus communis leaf extracts against organophosphate and pyrethroids resistant Rhipicephalus (Boophilus) microplus. Veterinary Parasitology, 18, 259267.

[26] Kodjo, T.A., Gbénonchi, M., Sadate, A., Komi, A., Yaovi, G., Dieudonné, M. and Komla, S. (2011) Bio-insecticidal effects of plant extracts and oil emulsions of Ricinus communis L. (Malpighiales: Euphorbiaceae) on the diamondback, Plutella xylostella L. (Lepidoptera: Plutellidae) under laboratory and semi-field conditions. Journal of Applied Biosciences, 43, 2899-2914.

[27] Babarinde, S.A., Oyegoke, O.O. and Adekunle, A.E. (2011) Larvicidal and insecticidal properties of Ricinus communis seed extracts obtained by different methods against Tribolium castaneum Herbst (Coleoptera: Tenebrionidae). Archive of Phytopathology and Plant Protection, 44, 451-459.

http://dx.doi.org/10.1080/03235400903093220

[28] Lv, C., Zhong, B., Zhong, G., Weng, Q., Chen, S., Hu, M., Sun X. and Qin, W. (2012) Four botanical extracts are toxic to the hispine beetle, Brontispa longissima, in laboratory and semi-field trials. Journal of Insect Science, 12, 58.

[29] Pacheco-Sánchez, C., Villa-Ayala, P., Montes-Belmont, R., Figueroa-Brito, R. and Jiménez-Pérez, A. (2012) Effect of Ricinus communis extracts on weight and mortality of Scyphophorus acupunctatus (Coleoptera: Curculionidae). International Journal of Applied Science Technology, 2, 83-94.

[30] Oparaeke, A.M., Dike, M.C. and Amatobi, C.I. (2005) Evaluation of botanical mixture for insect Pest management on cowpea Plants. Journal of Agriculture and Rural Development in the Tropics and Subtropics, 106, 41-48.

[31] Jackai, L.E.N. and Adalla, C.B. (1997) Pest management practices in cowpea: A review. In: Singh, B.B., Mohan Raj, D.R., Dashiella, K.E. and Jackai, L.E.N., Eds., Advances in Cowpea Research, Co-Publication of International Institute of Tropical Agriculture (IITA) and Japan International Research Centre for Agricultural Sciences (JIRCAS), Ibadan, 240-258. 